\title{
A mesa do rei - um estudo para a tradução e a interpretação do salmo 23
}

\author{
Osvaldo Luiz Ribeiro*
}

\section{Resumo}

Pesquisa exegética, com objetivo de preparar a tradução e a interpretação do Salmo 23. $\mathrm{O}$ artigo investiga a relação entre quatro elementos narrativos do salmo: a figura do deus-pastor, a plausível identidade monárquica do autor implícito e a identidade dos inimigos mencionados, bem como, o significado da mesa que o deus-pastor prepara para o salmista na presença daqueles inimigos. A literatura especializada interpreta de forma variada os elementos mencionados e, por isso, também o próprio salmo. Metodologicamente, o artigo investiga o campo semântico-fenomenológico da Bíblia Hebraica na procura de indícios referenciais-traditivos para a elucidação do sentido daqueles elementos e do salmo como um todo. Concluiu-se, provisoriamente, tratar-se da situação de um rei, ameaçado por não identificados inimigos, e que confia na intervenção do deus-pastor e em sua disso decorrente vitória, descrita de forma referencial-traditiva na forma da mesa real preparada diante dos inimigos derrotados.

Palavras-chave: Salmo 23. Salmos. Mesa do rei. Exegese. Bíblia Hebraica.

\section{The king's table - a study for the translation and interpretation of psalm 23}

\section{Abstract}

Exegetical research, in order to prepare the translation and interpretation of Psalm 23. The article investigates the relationship between four narrative elements of the psalm: the figure of shepherd-God, the plausible monarchical identity of the implied author and his mentioned enemies, and the meaning the table that shepherd-God prepares for the psalmist in the presence of those enemies. The research interprets in different ways the elements mentioned and therefore also the psalm itself. Methodologically, investigates the semantic-phenomenological field of the Hebrew Bible in search of referential and traditive evidences to elucidate the meaning of those elements and the psalm as a whole. It was concluded provisionally that this is the situation of a king,

\footnotetext{
Faculdade Unida de Vitória. Doutor em TeologiaProfessor do Departamento de PósGraduação Em Ciências das ReligiõesFaculdade Unida de Vitória.

E-mail: osvaldo@faculdadeunida.com.br.
} 
threatened by unidentified enemies, and that relies on the intervention of shepherdGod and his addition resulting victory, described in referential and traditive way as the actual table prepared before the defeated enemies.

Keywords: Psalm 23. Psalms. King's table. Exegesis. Hebrew Bible.

\section{La mesa del rey - un estudio para la traducción y la interpretación del salmo 23}

\section{Resumen}

Investigación exegética, con el fin de preparar la traducción y la interpretación del Salmo 23. El paper investiga la relación entre los cuatro elementos de la narrativa del salmo: la figura del dios-pastor, la identidad monárquica plausible del autor implícito y los enemigos mencionados y la significación de la mesa que el dios-pastor prepara para el salmista en presencia de estos enemigos. La literatura interpreta en diferentes maneras los elementos mencionados y por lo tanto también el salmo en sí. Metodológicamente, el paper investiga el campo semántico-fenomenológico de la Biblia Hebrea en busca de pruebas referencias-traditivas para dilucidar el significado de estos elementos y el salmo en su conjunto. Concluyese provisionalmente que esta es la situación de un rey, amenazado por enemigos no identificados, y que se basa en la intervención del diospastor y en la victoria resultante, que se describe en el camino referencial-traditivo de la mesa real preparada delante de sus enemigos derrotados.

Palabras clave: Salmo 23. Salmos. Mesa del rey. Exégesis. Biblia Hebrea.

\section{Introdução}

O objetivo do presente artigo é sugerir uma interpretação para a mesa que o salmista tem esperança de que a divindade lhe há de preparar, na presença de seus inimigos. Em torno do tema da mesa encontram-se, portanto, outros, que, então, precisam ser também analisados. No conjunto, são esses os temas: a) o motivo do deus-pastor, b) a identidade do autor implícito, que apela ao deus-pastor, c) a identidade dos inimigos mencionados na composição e sua relação com a identidade de seu autor implícito e, finalmente, d) o motivo e o significado da mesa que lhe será preparada pelo deus-pastor na presença daqueles inimigos. Este estudo constitui um passo intermediário entre, de um lado, a discussão mais técnica da tradução do verbo no versículo 1, tradicionalmente vertido como "nada me faltará", e nesse exercício traduzido como "não faltarei", ${ }^{1}$ e, de outro, a interpretação propriamente dita da composição como um todo. ${ }^{2}$ Sem preocupações estético-literárias, e apenas a título de tradução literal e provisória do Salmo 23, apresenta-se o quadro a seguir:

\footnotetext{
1 Para a argumentação técnico-exegética a favor da tradução "não faltarei”, cf. Ribeiro, 2017a.

2 Para a referida interpretação do Sl 23, cf. Ribeiro, 2017b.
} 


\begin{tabular}{|c|c|c|}
\hline \multicolumn{3}{|r|}{ Salmo $23^{\mathrm{I}}$} \\
\hline 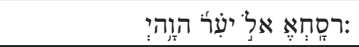 & 1 & Yahweh é meu pastor, não faltarei. ${ }^{\text {II }}$ \\
\hline 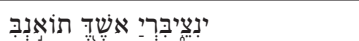 & $2 \mathrm{a}$ & Em pastagens ${ }^{\text {III }}$ de grama, ${ }^{\text {IV }}\left(\right.$ ele) me fará deitar. ${ }^{\mathrm{V}}$ \\
\hline 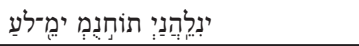 & $2 \mathrm{~b}$ & Junto de águas de descansos, (ele) me conduzirá. \\
\hline 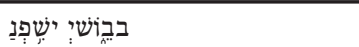 & 3a & A minha garganta ${ }^{\mathrm{VI}}(\mathrm{ele})$ restaurará. \\
\hline 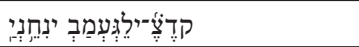 & 3ba & Guiar-me-á por sendas de justiça, ${ }^{\mathrm{VII}}$ \\
\hline 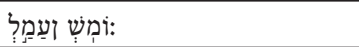 & $3 \mathrm{bb}$ & por causa do nome dele. \\
\hline 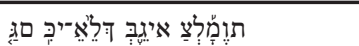 & 4aa & Mesmo que (eu) caminhe pelo vale da sombra, ${ }^{\mathrm{VIII}}$ \\
\hline 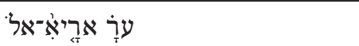 & $4 \mathrm{ab}$ & não temerei desgraça, ${ }^{\mathrm{IX}}$ \\
\hline 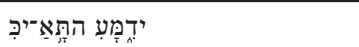 & $4 \mathrm{ac}$ & porque tu (é que) estás comigo. \\
\hline 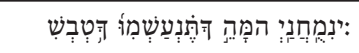 & $4 \mathrm{~b}$ & O teu bastão e o teu cajado, ${ }^{\mathrm{X}}$ eles (é que) me tranquilizarão. \\
\hline 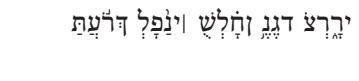 & $5 a$ & $\begin{array}{l}\text { Prepararás diante de mim uma mesa na presença dos meus ini- } \\
\text { migos! }\end{array}$ \\
\hline 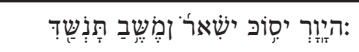 & $5 \mathrm{~b}$ & Ungiste $^{\mathrm{XI}}$ com óleo a minha cabeça, ${ }^{\mathrm{XII}} \mathrm{o}$ meu cálice, de plenitude... \\
\hline 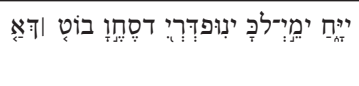 & 6a & $\begin{array}{l}\text { Certamente, bondade e misericórdia me seguirão todos os dias } \\
\text { de minha vida, }\end{array}$ \\
\hline 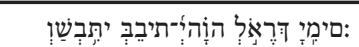 & 6b & e habitarei na casa de Yahweh pela extensão dos dias. \\
\hline
\end{tabular}

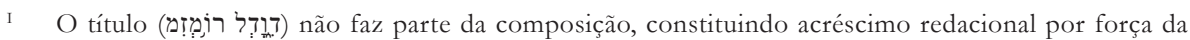
inclusão do salmo em coleção de composições, de sorte que se deve abster de extrair dele conclusões exegéticas relacionadas ao conteúdo mesmo do poema (cf. KRAUS, 2009, p. 472 e 28-46).

II Cf. a nota 1.

III "Pastagens", cf. Alonso-Schökel, 1997, p. 424.

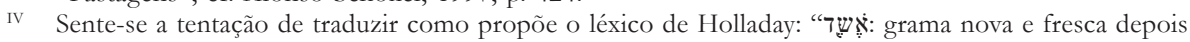
da chuva" (HOLLADAY, 2010, p. 103).

v Expressa por meio do mesmo verbo hebraico, tendo por sujeito ainda a divindade, mas agora apascentando todo o povo, cf. a mesma ideia em Ez 34,15.

vi Para a tradução "garganta", cf. Clines, 2001, p. 724 ("palate, throat") e Schökel, 1997, p. 442 ("na esfera da respiração: alento, respiração; seu órgão: garganta, pescoço"). Paralelamente à menção à potência semântica do termo, indicada nos dicionários citados, convém assinalar o caráter concreto da cultura hebraica. Para a interpretação geral do salmo, cf. nota 2.

VII Não se encontra no verbete explicação para o motivo, mas Alonso-Schökel sugere que, especificamente

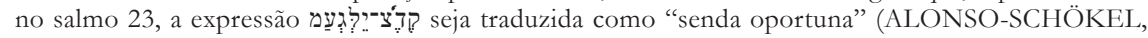
1997, p. 387).

VIII O comentário "a relação com o reino ou país da morte favoreceu a leitura לצ - לצ' sombra da morte" consta do verbete, que apresenta para לצ os sentidos de "escuridão, treva, caligem, obscuridade, sombra" (ALONSO-SCHÖKEL, 1997, p. 561).

Ix Para a tradução "desgraça”, cf. Schökel, 1997, p. 622 (“desgraça, calamidade”). O personagem teme a morte - trata-se, salvo melhor juízo, da desgraça das desgraças. Para a interpretação geral do salmo, cf. nota 2.

x Para a figura do bastão e do cajado, cf. Zacarias 11,7: "e eu tomei para mim dois cajados: a um eu

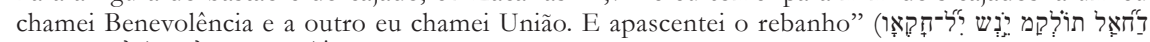

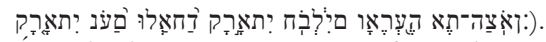

XI É a primeira vez no texto que a forma do completo é empregada. Até aqui, todos os verbos foram grafados no incompleto - e sem emprego do vav conversivo. Para a tradução "ungir", cf. Terrien, 2003, p. 237.

xil "Tu ungiste minha cabeça com óleo" (WASSERMAN e SZWERTSZARF, s/d, p. 84). 
No corpo do artigo, serão analisadas as figuras do deus-pastor, a possível e plausível identidade do "rei-salmista", a ameaça por ele sofrida por parte de inimigos não identificados e, finalmente, à luz do conjunto, o significado da mesa que o deus-pastor, ele crê, há de lhe preparar.

\section{Na Bíblia Hebraica, o "Deus" como pastor do povo}

"Yahweh é meu pastor." Na Bíblia Hebraica, encontrar o deus descrito como pastor ou pastoreando o povo não é um fenômeno incomum, de sorte que, à primeira vista, o salmista do Salmo 23 dirigir-se a Yahweh como seu pastor não tem nada de inusitadamente excepcional. Na verdade, na Bíblia Hebraica, seja na forma de substantivo ("pastor"), seja na forma de verbo ("pastorear" - "apascentar"), três grandes conjuntos de uso da figura do pastor podem ser identificados: a) o uso que se refere especificamente aos pastores enquanto tais, pastores de gado miúdo e graúdo, b) o uso que se refere ao deus como "pastor" do povo e, dada à questão não resolvida da identidade do salmista, o uso que mais interessa ao presente estudo, c) o uso da figura do pastor aplicada à liderança do povo, no âmbito do qual se sobressai um nome: Davi, "pastor" que Yahweh põe sobre o povo.

O conjunto prosaico referente à função pastoral propriamente dita não será tratado no presente estudo. Uma vez que interessa apenas investigar indiciariamente (GINZBURG, 1989, p. 143-180) a razão pela qual, ao deus invocado, o Salmo 23 aplica a figura do pastor, e, mais ainda, perscrutar a possibilidade de quem se situa no horizonte de invocação do salmo poder ser interpretado como um rei (EATON, 1965, 171-173), sobre o qual, extensivamente, recai a figura de "pastor" do povo, parece justificada a decisão quanto a somente duas das três coleções de passagens serem analisadas - de um lado, o deus como "pastor", e, de outro lado, os líderes de Israel e de Judá como "pastores".

Na Bíblia Hebraica, a relação retórica entre "deus" e "pastor" pode ser construída de três modos. Em primeiro lugar, pode-se simplesmente comparar a ação do deus a de um pastor. Não se vai diretamente ao nível da metáfora. Permanece-se no nível da comparação. Em Jeremias 31,10, se diz que "o que espalhou Israel o recolherá e o guardará, como um pastor, o

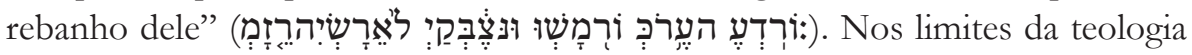
expressa, o responsável pela diáspora israelita é o deus israelita, de sorte que está subentendido que esse mesmo deus recolherá seu povo como um pastor recolhe as suas ovelhas, espalhando ele pelas nações, espalhadas elas pelos 
campos. Comparativamente, deus age como age um pastor. Teologicamente, como um redentor (UNTERMAN, 1987, p. 117).

Pode-se, todavia, aprofundar a figura de expressão e empregar o verbo "pastorear" para descrever o cuidado do deus com o povo. Não se diz ainda que o deus é um pastor, mas já se aplica ao deus o verbo próprio da profissão. É o caso, por exemplo, de Gênesis 48,15, onde se pode flagrar Jacó referindo-se ao deus como aquele que o pastoreou por toda a sua vida:

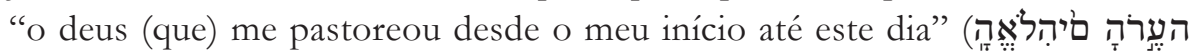

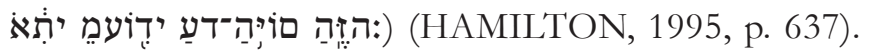

Essa mesma ideia - o deus "pastoreia" o povo - encontra-se em duas passagens que suplicam ao deus que pastoreie o seu povo. Trata-se do Salmo 28,9, onde o salmista roga à divindade que salve e "apascente" o seu povo:

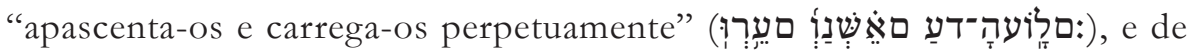
Miqueias 7,14, onde outra vez a divindade é chamada a pastorear seu povo: "apascenta o teu povo com o teu bastão, o rebanho da tua herança" (העֶר)

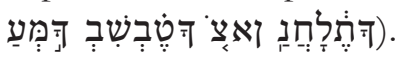

Da comparação do deus com um pastor, passando pelo uso do verbo "pastorear", aplicado ao trato do deus com Israel, chega-se ao "clímax" da metáfora. No Salmo 80,2, a divindade é chamada de "pastor de Israel” הيֶֶ)

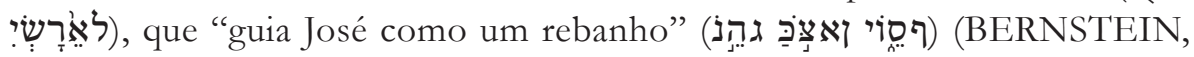
2005, p. 494), e talvez seja também ao deus que se dirija a expressão "único pastor" de Eclesiastes 12,11 (דחקֶ העָ (D'ALARIO, 1992, p. 207). É natural supor que já no nível da comparação se podia inferir o uso da figura do pastor como referência ao deus, e que o nível de alusão se ampliava significativamente ao se empregar o verbo "pastorear" ou "apascentar" com esse mesmo objetivo. Todavia, a metáfora explicita radicalmente a relação entre os termos e as figuras "deus" e "pastor". Deus age como pastor, isto é, pastoreia como pastor, porque é pastor...

Pode-se, portanto, agora, conceber que não se trata de fórmula original a empregada no Salmo 23,1. "Yahweh é meu pastor" traduz um tema presente na noosfera subjacente à Bíblia Hebraica. No entanto, pode-se concluir que ela opera no nível mais alto de seu testemunho: não fala de comparação e não usa apenas um verbo da especialidade pastoril. Antes, trata diretamente o deus como pastor. Mais do que isso: seu pastor: "Yahweh é meu pastor" (KRAUS, 2009, p. 472).

Além disso, trata-se de uma declaração que parece indicar intimidade (CROFT, 1987, p. 130). Se, de um lado, Yahweh é pastor do povo, de outro 
lado o salmista trata o deus pessoalmente - "meu pastor". Esse testemunho não se aplica, na fenomenologia da Bíblia Hebraica, ao povo. O povo é rebanho no coletivo, do qual Yahweh é, sim, pastor. Mas o salmista não parece se enquadrar no conjunto do rebanho. Sua relação com Yahweh é, parece, de outro nível: Yahweh é o seu pastor. Isso deve apontar - é o que também conclui o autor já citado - para a identidade monárquica do salmista. Em termos metodológicos, deve-se perguntar se temos aí um "indício"3 (GINZBURG, 1989, p. 143-180).

\section{Na Bíblia Hebraica, os líderes do povo como pastores}

De diversos modos, a Bíblia Hebraica aplica a lideranças políticas o verbo "pastorear" ou o substantivo "pastor". Em um conjunto considerável de passagens, o termo "pastor" é empregado indistintamente a uma ou várias figuras relacionadas à divindade e postas sob função de liderança ( Jr 8; 3,15; 10,21; 22,22; 23,1.2.4; 49,19; 50,6; Zc 11,4.5.7.8.9.15.16; 11,17; 13,7). Mas há outros casos, mais pessoais e explícitos.

Considerando-se uma classe política inteira, em Naum 3,18, todo o segundo escalão ${ }^{4}$ do governo assírio é tratado como "pastores": "dormem

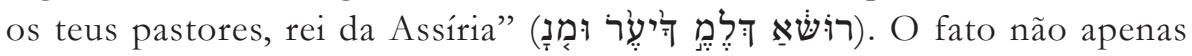
é apontado na literatura, mas também é justificado com o argumento de que "pastores' pode também referir-se à família real" ("shepherd's may also refer to the royal family"; COGGINS e HAN, 2011, p. 34). Por sua vez, pensando-se não em toda uma família real ou em uma classe inteira de políticos, mas em uma pessoa específica, em Isaías 44,28 Ciro é apontado como "pastor de Yahweh": "o que diz de Ciro: é o meu pastor, e tudo o que

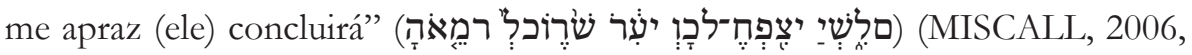
p. 158). Assírios e persas: percebe-se que o termo "pastor" pode ser aplicado a políticos estrangeiros, no estrangeiro, a políticos estrangeiros, em Israel, e a políticos de Israel. Não há prerrogativas de exclusividade. Não se trata de uma ideia "nacional", mas próximo-oriental. Aplica-se tanto a políticos de Israel quanto a políticos de qualquer país, seja da Assíria, seja da Pérsia.

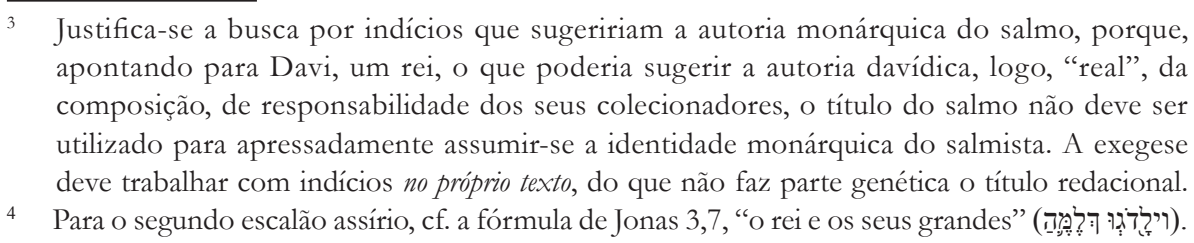


Também do próprio Israel, obviamente. Por exemplo, dependendo da correção ou não do texto hebraico, em 2 Samuel 7,7 (= 1 Cr 17,6), descobrese que a divindade colocara ou uma "tribo" ou um "juiz" para "pastorear o

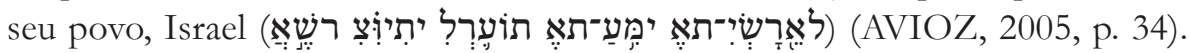
Em Números 27,17, pede-se um homem que seja posto sobre a congregação inteira do povo, para que esta não acabe como um "rebanho que não tem

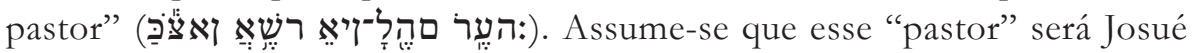
(COLE, 2000, p. 468-469). Em Miqueias 5,3, a quase mítica figura do "juiz de Israel" ergue-se desde os dias antigos para se tornar aquele que "apascentará" Israel: "ele se porá e apascentará, com a força de Yahweh, com a altura do

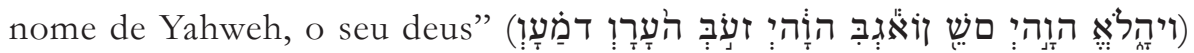
(MASON, 2004, p. 51). Espera-se que o "pastor" de Yahweh, pastor para o povo, apascente o povo de Yahweh.

Nem sempre, todavia, trata-se de evocar a figura do pastor para delinear ideias de cuidado e proteção. Ao contrário, pode-se aplicar a metáfora para descrever em chave figurativa o estrago provocado, por exemplo, por um exército, se comparado ao estrago em consequência do consumo voraz dos pastos pelos rebanhos. É o caso de Miqueias 5,4-5, segundo o qual a Assíria

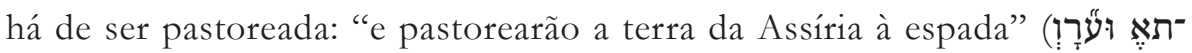

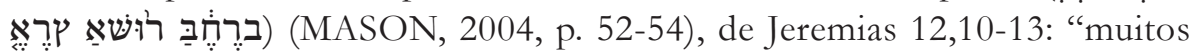

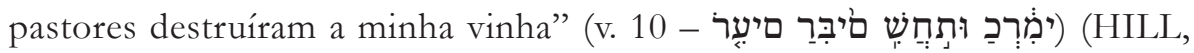
1999, p. 71) e de Jeremias 6,3, segundo a qual pastores entram em Jerusalém e a destroem com seus rebanhos de pastagem: "nela entram pastores e seus

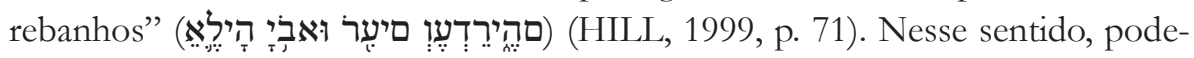
se compreender por que Jeremias 25,34-36 compara os líderes do povo aos pastores, os "principais do rebanho" (v. 34), para os quais não haverá tempo para fuga (v. 35), só para gritar, quando Yahweh destruir o seu pasto (v. 36).

Por seu turno, Ezequiel 34 é um capítulo inteiro dedicado a tratar metaforicamente os líderes de Judá como "pastores" (KAMIONKOWSKI, 2003, p. 50-51). Ezequiel 34,2 inicia com a ordem para que o profeta profetize contra os líderes de Israel: "filho de homem, profetiza contra os pastores

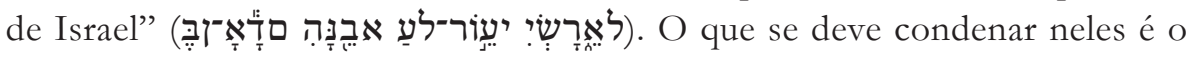

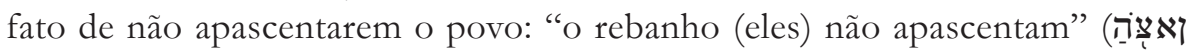

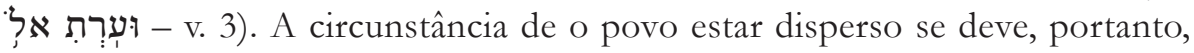
a isso: o povo não tem pastor, diz o versículo 5, as ovelhas "espalharam-se

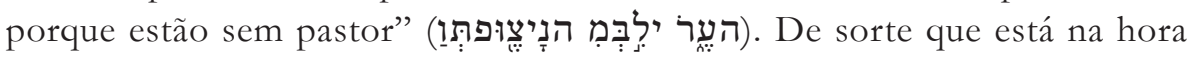
de os "pastores" ouvirem a palavra do deus: "por isso, pastores, ouvi a 


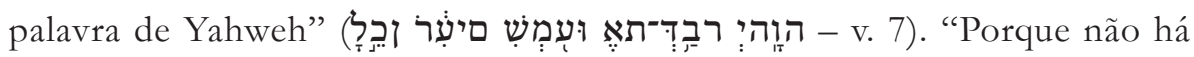
pastor, e não buscam os meus pastores o meu rebanho, e apascentam-se a

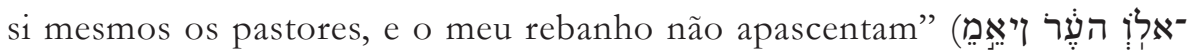

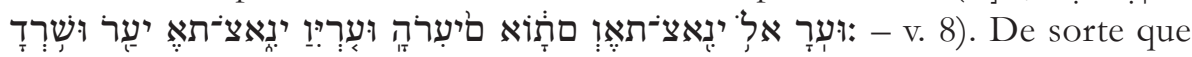
os pastores devem ouvir, de novo, a palavra de Yahweh (v. 9), que declara que a divindade tomará das mãos dos pastores o seu rebanho, para que as ovelhas não sirvam de pasto para os próprios pastores, que se apascentam a si mesmos (v. 10). Como faz um pastor, quando estão dispersas, a divindade irá ela mesma buscar as suas ovelhas (v. 12), e, trazendo-as da dispersão, ela mesma, a divindade, as apascentará em Israel: “e as apascentarei nos

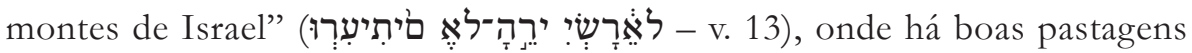
(v. 14), de sorte que "eu mesmo apascentarei o meu rebanho, e eu mesmo as farei repousar, oráculo do senhor Yahweh” (v. 15 - 15 -

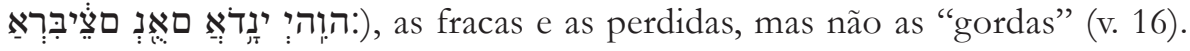
Porque a divindade vai separar ovelhas de ovelhas (v. 18), preocupado com as prejudicadas pelas fortes (v. 19). Como a divindade fará isso? Levantando sobre elas um só pastor, Davi (v. 23).

\section{Na Bíblia Hebraica, Davi como o rei-pastor}

$\mathrm{Na}$ esteira de perguntar-se sobre a possibilidade da identidade real do autor implícito do Salmo 23, encontrar na Bíblia Hebraica um conjunto proporcionalmente significativo de referências a Davi como rei-pastor é sugestivo. Em 2 Samuel 5,2 (= 1 Cr 11,2) (CAMPBELL, 2005, p. 56), as "tribos" de "Israel" fazem saber a Davi que eles o escolhem e aceitam, e que Yahweh teria declarado que ele, Davi, haveria de apascentar o seu povo: "Yahweh disse para ti: 'tu apascentarás o meu povo, Israel, e tu serás líder

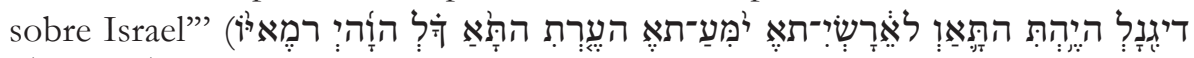

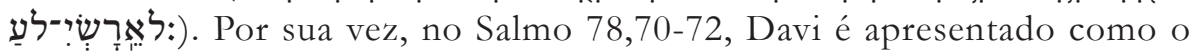
escolhido de Yahweh que foi tirado de trás das ovelhas para apascentar o povo (WEISER, 1994, p. 410):

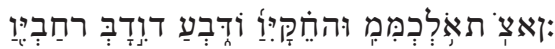

E escolheu Davi, seu servo, e o tirou do aprisco das ovelhas.

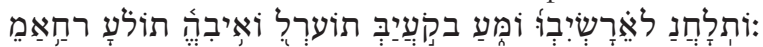

De trás das pejadas o tirou, para pastorear Jacó, o seu povo, e Israel, a sua herança.

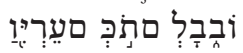

E (ele) os apascentou conforme a integridade do seu coração... 
Outra vez ainda Davi é chamado de pastor: "e o meu servo Davi será

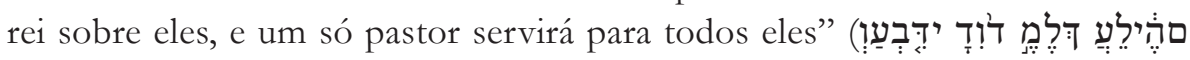

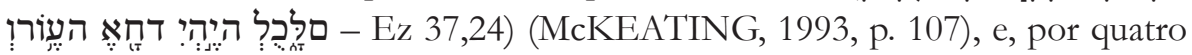
vezes, Ezequiel 34,23 chama Davi de pastor do povo (McKEATING, 1993, p. 106-107):

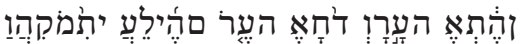

E levantarei sobre eles um só pastor, e ele as pastoreará

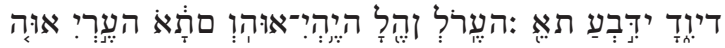

O meu servo Davi, ele os apascentará, e ele lhes servirá de pastor.

Há de se levar em conta que essa concentração da figura do pastor sobre a memória do rei Davi se deva mais à recepção da tradição messiânica (HANN, 2012, p. 47-50), e que essa mesma tradição esteja diretamente relacionada ao título redacional escolhido para a composição. A tradição teológica relacionada à coroa opera sobre a escolha do nome de Davi para o título, há que se admitir. Todavia, a estreita relação tradicional entre Davi e Yahweh, propicia a percepção de equivalente figura monárquica no Salmo 23, no sentido do tratamento íntimo e personalíssimo pressuposto entre o autor implícito e a divindade. Com o que se deve reconhecer nada mais do que um eco da declaração de Croft: "um relacionamento especial entre Yahweh e o salmista" ("a special relationship between Yahweh and the psalmist"; CROFT, 1987, p. 130). Admitamos, todavia, tratar-se de um movimento talvez rápido demais. É indiscutível que o salmista se dirige a Yahweh, tratando-o como pastor, o que denuncia a imagem do deus-pastor. No entanto, daí não se deduz automaticamente tratar-se o salmista necessariamente de um rei salvo, claro, se a intimidade de tratar o deus-pastor como meu pastor trair sua identidade real. Felizmente, para a investigação e defesa da hipótese dessa identidade ser monárquica há outros argumentos.

\section{Considerações sobre o tratamento na Bíblia Hebraica de políticos como pastores}

Como primeira aventura na argumentação da sugestão da identidade monárquica do salmista, convém algumas considerações sobre o tratamento do contingente político como "pastor". Os inúmeros casos identificados na Bíblia Hebraica parecem transparecer uma tática retórica comum às monarquias próximo-orientais. Com efeito, "a figura e o título de rei e da 
divindade como pastor se estende a área cultural muito ampla" (ALONSOSCHÖKEL e CARNITI, 1996, p. 381). Demagogicamente, o rei se legitima como posto no trono pelo respectivo deus, com a função de "pastorear" o rebanho divino - o povo. Datada do século XVIII a.C., já tão cedo, a famosa estela de Hammurabi testemunha o uso do termo "pastor" aplicado a um monarca babilônico. "Eu sou Hammurabi, o pastor" (BOUZON, 2003, p. 40), pode-se ler logo no início das inscrições, e, mais abaixo, de novo: "pastor dos povos" (BOUZON, 2003, p. 45).

Está-se aí diante da tática demagógica da monarquia. Nesses termos, o rei se declara posto pelo deus na posição em que está - como pastor do povo - para cuidar do povo, que, nesse sentido, então, assume a condição de ovelha e rebanho. O discurso encontra-se presente na estela citada: "Hammurabi, o príncipe piedoso, temente a deus, para fazer surgir a justiça na terra, para eliminar o mau e o perverso, para que o forte não oprima o fraco, para, como o sol, levantar-se sobre os cabeças-pretas" (BOUZON, 2003, p. 40).

Aplicado retoricamente a Hammurabi, a figura do pastor ilustra, metaforicamente, a promessa do rei da garantia da justiça. Encarando o monarca como pastor, mais do que como rei, o povo deve sentir-se cuidado e protegido, deve ter como garantida a prática da justiça, deve sentir-se protegido da opressão comezinha do dia a dia, tanto quanto da opressão militar dos povos estrangeiros. O povo não dispõe de um rei apenas. O povo dispõe de um pastor, alguém que cuida dele. Cabe, portanto, a esse povo, em troca da segurança e do cuidado, manter esse rei-pastor.

Em termos práticos, o cuidado do rei-pastor se traduz no estabelecimento e no cumprimento das leis. Sobretudo na garantia de que ela vale para todos e de que sobre todos será aplicada como condição de justiça e de percepção de justiça. Segundo Bouzon, essa teria sido justamente uma das questões centrais da preocupação de Hammurabi:

Uma de suas primeiras preocupações foi (...) a implantação do direito e da ordem no país, fundamento da unidade interna do reino (...). A vasta correspondência com os seus funcionários de Larsa, Sn-iddinam e Shamashhazir atesta o esforço enorme e a vontade incansável de fazer reinar a justiça em seu império (BOUZON, 2003, p. 21).

Bem, não dispomos da opinião do povo a respeito da efetividade das intenções do rei. Mas dispomos das cartas a que Bouzon se referiu 
(BOUZON, 1986) e, se elas não atestam necessariamente que tais preocupações se efetivavam em reais medidas práticas, elas, ao menos no nível das tabuinhas, revelam exatamente as preocupações assinaladas. Por exemplo, em uma das cartas, Hammurabi escreve aos seus representantes em Larsa que intervenham na arbitrariedade de um oficial local que impedia o acesso do proprietário ao seu campo (BOUZON, 1986, p. 159). Em outra, Hammurabi decide que a propriedade há tanto tempo confiada a um grupo de pessoas deve ser mantida em sua posse (BOUZON, 1986, p. 175). Um império a administrar, e o rei preocupando-se com questões tão aparentemente pequenas. Mas a garantia de direitos e de terras traduz-se exatamente no que se pretende transmitir quando se é apresentado ao povo como o seu "pastor".

A Bíblia Hebraica não desconhece o regime demagógico e retórico da figura do rei-pastor. Ao contrário, como se viu, serve-se dele. A despeito de poder ser identificado pelo levantamento das atualizações da raiz הער, seja aplicado especificamente ao rei, seja inflacionado às lideranças políticas da corte, o regime retórico-demagógico do "rei-pastor" pode, na Bíblia Hebraica, ser flagrado também por meio de outros procedimentos exegéticos.

Dois exemplos. Na Bíblia Hebraica, o termo técnico هִדָָ "filhos de Adão" ou "filhos de homem") designa a corte em torno do rei, seus oficiais e funcionários, sacerdotes, profetas cúlticos, militares, secretários etc. (RIBEIRO, 2011). Conforme se pode concluir do texto em referência, em oito ocorrências (Dt 32,8; 2 Sm 7,14; Sl 21,11; 36,8; 45,3; 53,3 = 14,3; 58,2; $\left.89,4^{5}\right)$, a questão se decide. Em duas delas, há jogo retórico entre a figura do rei e dos seus oficiais como "pastores" e o tratamento que dispensam ao povo. Vejamos cada caso.

No Salmo 58, o salmista inquire os "filhos de Adão" se é verdade que julgam com imparcialidade e justiça (v. 2). É uma pergunta retórica, e o mesmo salmista responde que não, que a corte gera perversão e promove a violência (v. 3), que os homens da corte mentem e servem-se da companhia dos ímpios (v. 4), são venenosos e surdos a qualquer denúncia e reclamação do povo (v. 5-6). Nesse ponto, tomado de indignação, o salmista dirige-se à divindade: "Deus, quebra-lhes os dentes da boca! Arranca-lhes as presas aos

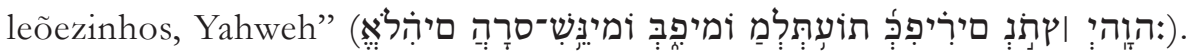
Segue-se uma série de pragas (v. 7-10) e, então, a declaração de que, quando

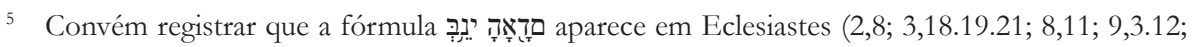
$12,12)$, algumas vezes com o sentido que presentemente se analisa. 
Yahweh fizer o que tem de fazer, o justo verá que realmente há justiça na terra (v. 11-12). Parece adequado considerar que a chave para compreender

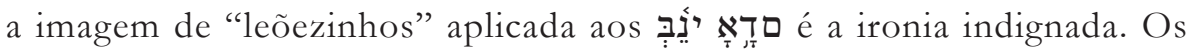

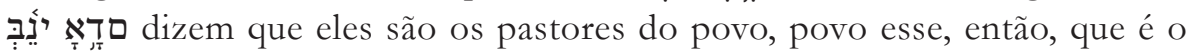
rebanho que eles pastoreiam. Como pastores do povo, eles devem protegê-lo

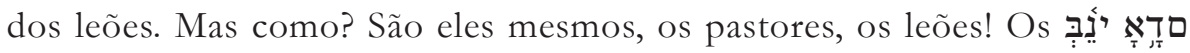
não apenas deixaram de promover a justiça - eles promovem a injustiça.

O outro caso é o Salmo 53 (RIBEIRO, 2014). Concentrando-nos no

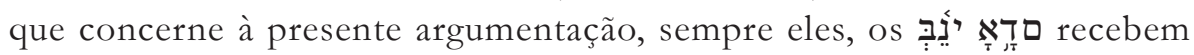
uma "visita" de Yahweh, que pretende verificar se estão agindo conforme seu dever - cuidar do povo de Yahweh. A constatação não poderia ser mais grave: em lugar de estarem cuidando do povo de Yahweh, os "filhos de Adão" estão devorando o povo de Yahweh: "acaso não têm entendimento

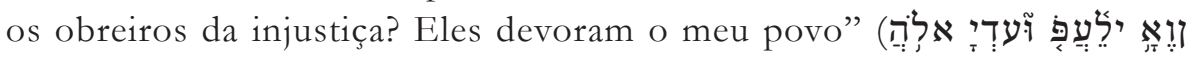

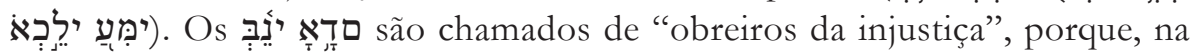
condição de obreiros de Yahweh para a justiça, em lugar de serem flagrados promovendo-a, são flagrados na prática justamente do seu contrário. Em lugar de cevarem o povo, ceifam-no. Em lugar de cuidarem dele, devoramno. Em vez de serem pastores, outra vez, convertem-se na própria ameaça que deveriam prevenir.

Essa é a versão negativa do regime rei-pastor, que não tivemos oportunidade de ouvir em relação a Hammurabi, do qual soubemos, conforme quer Bouzon, ter estado empenhado maximamente na promoção da justiça.

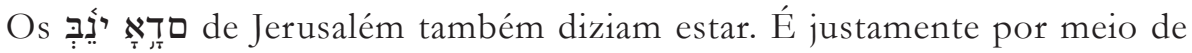
sua retórica de cuidado, pelo fato de se apresentarem como reis-pastores, que o povo conhece a demagogia oficial.

Também na Bíblia Hebraica, o trono do rei funda-se na justiça. É o mesmo que se pode ler sobre Hammurabi. O Salmo 89 é uma excelente peça para demonstrá-lo. A função e o dever reais são promover a justiça, justiça essa que está na base do trono de Yahweh e, por extensão, na base do trono de seu ungido, o rei de Jerusalém (RIBEIRO, 2009). Talvez se pudesse sugerir que a fórmula "guiar-me-á por sendas de justiça" apontasse para esse compromisso de exercício funcional relacionado à identidade do salmista: sobrevivendo à ameaça dos inimigos, o rei-pastor espera retornar aos campos, às águas, à restauração e, finalmente, à justiça, de que tem dever de dar conta (cf. Sl 45,7). 


\section{Indícios no Salmo 23 sobre a identidade monárquica do autor implícito}

Não se trata, ainda, de fazer uma exegese completa do Salmo $23 .{ }^{6}$ Nesse momento, trata-se de buscar na composição os indícios plausíveis da identidade monárquica do salmista. Se de fato se trata de um autor implícito cuja identidade é monárquica, a composição estaria marcada por alguma característica própria dessa subjetividade real. Ainda que não se tratasse de um texto de propaganda da figura real, como o "Código" de Hammurabi (BOUZON, 2003, p. 28), mesmo que se trate de um texto personalíssimo e de real sofrimento, as marcas identitárias hão de ter sido plasmadas na forma de pensamento, de expressão, de referência.

Ao lado, portanto, do tratamento íntimo dirigido ao deus como seu pastor $(\mathrm{S} 1$ 23,1) e da referência ao seu retorno às sendas de justiça (S1 23,3), como o mais gritante indício da plausível identidade real do autor implícito do salmo, considere-se que se encontra a referência àquilo que aqui se interpreta como a própria coroação do rei: "ungiste com óleo a minha cabeça" (v. 5) (CROFT, 1987, p. 130). "Ungiste" - trata-se de um verbo. E com essa constatação, deparamo-nos com a primeira evidência de que estamos diante de um centro de gravidade da narrativa. Em todos os versículos do salmo há emprego de verbos. Em todos os casos, exceto um, os verbos encontram-se no incompleto. O único verbo que se encontra grafado no completo é o verbo ושד ("ungir"). ${ }^{8}$ O que isso significa? Bem, da forma como vejo, em termos sintáticos, o salmista está pensando o tempo todo a respeito da tensão entre presente e futuro. No presente, no mesmo versículo 5, os inimigos o espreitam e representam a ameaça da qual resulta o salmo, porque é desse grave perigo que decorre seu temor, ao qual o salmista responde com sua declaração de fé e confiança "Yahweh é meu pastor, não faltarei". ${ }^{9}$ Esses inimigos representam risco - de vida! - para o salmista-rei, de sorte que o horizonte de eventos que o espera é potencialmente perigoso. Em face do perigo instalado e dos riscos iminentes, o salmista postula um futuro inversamente proporcional às circunstâncias. Os inimigos estão presentes,

\section{Cf. a nota 2 .}

"Ungir" (ALONSO-SCHÖKEL, 1997, p. 163); “unges" (KRAUS, 2009, p. 468).

8 Cf. nota anterior. Pelo menos duas outras passagens da Bíblia Hebraica podem servir de orientação para a presente interpretação. Para o uso da raiz como sinédoque dos "grandes da terra", o que pode apontar para o uso da raiz na referência aos nobres, cf. Sl 22,30. Para a concomitância do emprego da raiz e a referência a rei, cf. Jz 9,9.

9 Cf. nota 1. 
mas eles não vão vencer: amanhã, quando Yahweh preparar uma mesa para o rei, na presença de seus inimigos vencidos, a vitória final será do salmista, coroada a sua vitória por "um banquete para o rei na presença de seus inimigos, significando vitória" ("a banquet for the king in the presence of his enemies, signifying victory"; CROFT, 1987, p. 130).

À fé, portanto, o final parece garantido. Até chegar, contudo, a essa constatação, em face do perigo instalado, o salmista percorre caminhos de memória e confiança. As versões traduzem o conjunto dos verbos do Salmo 23 para o presente, porque talvez lhes pareça resultar mais poético. Seja como for, trata-se sempre, todavia, de verbos no incompleto (ou imperfeito), que, à luz da argumentação, designa o horizonte de esperança - confiança! - do salmista-rei. Uma a uma, as declarações vão descrevendo a memória-esperança do salmista, que declara que ainda será novamente levado aos campos de pastagens, será encaminhado a repousar próximo às águas tranquilas, terá sua garganta, sua vida, suas forças restauradas, será guiado pelas sendas da justiça... Sempre incompleto, sempre horizonte de esperança, confiança... E confiança, todavia, a despeito do cenário, já que lá estão os inimigos, e parece haver no salmista razões suficientes para temê-los. Mesmo nesse cenário, sempre no incompleto, o rei-salmista declara que nem assim temerá desgraça (ע) , porque o bastão ${ }^{10}$ e o cajado de Yahweh - seu pastor! - o deixarão em segurança. Se o risco de morte é o eixo semântico do salmo, o bastão e o cajado são o eixo da esperança (AHRONI, 1982, p. 30). Mais do que se declarar em segurança, caminhando pelo vale de sombras, sob a proteção do cajado e do bastão divinos, para o rei-pastor é certa, amanhã, a vitória sobre os inimigos, do que resulta a preparação de uma mesa (como se viu, de vitória e soberania) na presença dos derrotados (CROFT, 1987, p. 130). Ao fim e ao cabo, vitorioso e, sobretudo, vivo, o salmista-rei deseja e sabe que a bondade e a misericórdia - de Yahweh - o seguirão todos os dias de sua vida. Hoje, a ameaça dos inimigos - amanhã, sua derrota fragorosa, sua humilhação completa, e, para o poeta-monarca, o salmista-ovelha, o rei-pastor, uma vida de benevolência, sob os cuidados de Yahweh, em cuja casa o autor implícito pensa habitar "para sempre"...

10 "These two terms are not to be regarded as hendiadys; 'staff' (...) is not a mere rhetorical repetition, nor amplification of 'rod', but rather a designation of a totally different rod. Each of the rods (...) fulfills a distinct role: (...) 'rod' is an offensive weapon in the form of a club, used for the protection of the flock from robbers and beasts of prey; the 'staff' is an instrument in the form of a crook, used by the sheperd to guide the sheep, to maintain order within the flock, and as a means of support for the shepherd himself to facilitate his walking and climbing on rocks" (AHRONI, 1982, p. 26-27). 
Tudo isso, amanhã - incompleto. Ontem, apenas uma declaração: “ungiste com óleo a minha cabeça". Essa unção, essa "unção com óleo" "“anointing with oil"; CROFT, 1987, p. 130), é descrita por meio do verbo ושושד, atualizado no completo (ou perfeito). Toda a confiança quanto ao horizonte de eventos, descrito sempre com verbos no incompleto, sustenta-se nesse verbo no completo. A despeito da ameaça de vida, o rei-pastor "não faltará", ${ }^{11}$ antes, vencerá todos os inimigos, porque ele foi ungido pelo deus-pastor. Os inimigos não podem com o salmista-rei, porque as armas do deus-pastor serão brandidas contra eles, por causa daquele fato. O salmista é pastor de Yahweh, por causa daquele evento. Mas de que acontecimento se trata?

Bem, a depender da literatura, muitas são as possibilidades de explicação. Para Weiser, por exemplo, "a ação litúrgica terminou, os cânticos emudeceram, as pessoas, com ornamentos festivos e a cabeça ungida com óleo (...) aprestam-se para a alegre refeição sacrificial na casa de Deus" (WEISER, 1994, p. 165). Uma alegre refeição sacrifical na casa de Deus? E quem tem a cabeça ungida com óleo são as pessoas que se aprestam para a refeição? Mas como assim "as pessoas", se no salmo, o que se diz, e nada mais, é que "ungiste com óleo a minha cabeça?". E como elas se apresentariam, se a unção se deu ontem? Deixemos que seja sobre a mesa ser o caso de tratar-se de uma refeição sacrifical, mas não se pode passar em silêncio sobre a declaração de que as pessoas estão com a cabeça ungida de óleo. Que seja uma festa sacrifical, quem sabe?, mas o texto é claro: a) apenas o rei-pastor e salmista teve sua cabeça ungida e b) não é agora que a cabeça dele está ungida, foi “ontem", passado, completo, que o óleo se derramou.

Por sua vez, há quem proponha considerar que o óleo sobre a cabeça seja uma indicação do óleo que os pastores utilizam na cabeça das ovelhas, para lhes apressar a cicatrização de suas eventuais feridas (MORGENSTERN, 1946, p. 17). Nesse caso, após atravessar o vale das sombras e enfrentar os inimigos - que, para o autor citado, são as bestas do vale, e não seres humanos -, ferido da luta, o salmista-ovelha recebe do deus-pastor os curativos cicatrizantes... O acontecimento em que o salmista põe a sua confiança é uma celebração ritual ou, quem sabe, as seções de curativos do deus-taumaturgo?

Há mais, todavia. Na passagem citada de Weiser, a seção entre parêntesis corresponde à indicação não transcrita de dois versículos bíblicos,

11 Cf. nota 1. 
um dos quais é o Salmo 45,7. É curioso que ao descrever "as pessoas" com a cabeça ungida de óleo, Weiser recorra justamente ao Salmo 45,7, porque lá, tanto quanto cá, trata-se apenas e tão-somente do rei: "amas a justiça e odeias a injustiça - por isso ungiu-te Deus, o teu deus, com óleo de alegria mais

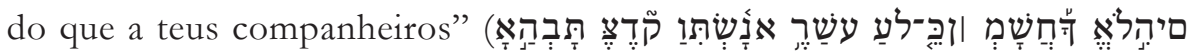

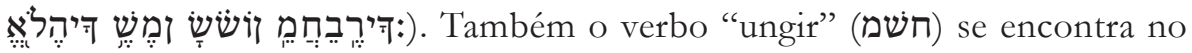
completo, exatamente como o verbo ושרד no Salmo 23,5. E é assim, porque o Salmo 45,7 se refere ao rito de entronização do rei, de modo que "ungiu-te" é uma sinédoque: toma-se o rito de unção para referir-se à entronização do rei. A majestade do rei deriva da unção naquele dia. Weiser indica a passagem, mas não parece extrair dela as inferências que aqui se vislumbram, porque, tanto no Salmo 45,7 quanto no Salmo 23,5, onde se tratava de uma pessoa sendo ungida, Weiser vislumbrou uma multidão. É verdade que o que se traduz como "ungir" no Salmo 23 (ושטד) (TERRIEN, 2003, p. 237) não é o mesmo verbo - clássico! - para "ungir" (חשמח) no Salmo 45,7. Todavia, não se pode esquecer o comentário de David Freedman: no Salmo 23, "o vocabulário, embora incomum, é bastante compreensível, e a gramática e a sintaxe enquadram-se no estilo hebraico clássico" ("the vocabulary while unusual is quite comprehensible, and the grammar and syntax are well within the range of classical Hebrew style", grifo do autor; FREEDMAN, 1976 , p. 139). Com isso, não se joga a diferença de raízes para debaixo do tapete, mas se argumenta que o campo semântico do salmo analisado não se atualiza por meio de "usual vocabularies". ${ }^{12}$ Por sua vez, se a "unção" do Salmo 23,5 não se dá à percepção imediatamente como referência ao rito de entronização do rei-pastor, tampouco se pode assumir que a perspectiva de uma festa cerimonial salta aos olhos diretamente do texto. Alonso-Schökel e Carniti, por exemplo, percebem um acontecimento totalmente distinto, nem entronização nem festa cerimonial nem seção de curativos, mas a chegada de um fugitivo na tenda de um xeque, que lhe unge a cabeça com "aromas" (ALONSO-SCHÖKEL e CARNITI, 1996, p. 383). Os inimigos do versículo 5 ? Bem, eles são os que ficam à porta, roendo-se de inveja do repasto hospitaleiro que o peregrino recebe... É justamente por isso que o peregrino se sente seguro na tenda do xeque: "qualquer agressão seria atentar contra os direitos sagrados da hospitalidade, seria ofensa ao anfitrião que o recebeu” (ALONSO-SCHÖKEL e CARNITI, 1996, p. 383). Como se vê, parece que

12 Cf., ainda, a nota 20. 
o texto não pode sugerir, sozinho, um caminho unívoco, de sorte que os comentaristas se esforçam na medida do comprometimento de seus olhos...

Festa cerimonial e sacrificial? O peregrino na tenda do xeque anfitrião? Uma seção terapêtica? Ou, ainda, o que prefere entrever Freedman: a imagem do "Exodus from Egypt, and its accompanying phenomena: the wandering through the wilderness, and the settlement in the domain of God" (FREEDMAN, 1976, p. 139)? Definitivamente, não se está pisando em terreno firme. Para tornar a situação ainda menos favorável para essa corrente de interpretações, anote-se que já se disse que "nenhuma das passagens que (...) (os defensores dessas interpretações) citam pode explicar os inimigos" (SYLVA, 1993, p. 86).

Nesse sentido, a estratégia hermenêutica deste artigo não é exatamente nova. Servindo-me de Croft:

Psalm 23 is (...) the best known (...) and there are several signs that the piece is a royal psalm: there is evidence of royal style ('my shepherd', v. 1); of a special relationship between Yahweh and the psalmist; of a banquet for the king in the presence of his enemies, signifying victory and, most significantly, an anointing with oil (CROFT, 1987, p. 130, grifos do autor).

Para Croft, trata-se de "unção" com óleo, e isso significa tratar-se da figura de um rei. Concordo, conquanto reconheça a condição movediça do terreno. Seja como for, a estratégia de Croft me parece adequada. A tática, todavia, talvez nem tanto. Porque o próprio Croft é da opinião de que "the reference to danger (v. 4) is too vague" (CROFT, 1987, p. 130). Ora, é justamente a dificuldade de ligar a proposta de tratar-se de um salmo real com os elementos internos do salmo que tem levado a tentativas radicais de interpretação, que chegam a propor correções no próprio texto hebraico (AHRONI, 1982, p. 25). O próprio Ahroni é crítico dos procedimentos de alteração do texto hebraico, e tenta, a seu modo, uma solução no campo hermenêutico. Ele reconhece, todavia, que:

Scholars have long noted that the abrupt transition from the figure of the deity as the good shepherd (v. 1-4) to that of the lavish and over-generous host (v. 5) disrupts the unity of thought in the Psalm. Far more disturbing, in the view of many scholars, is the phrase (...) 'in the presence of my enemies' (v. 5). It has been contended that this abrupt reference to enemies introduces an inexplicable note, which is "in jarring contrast" to the pastoral imagery and the idyllic character of this hymn of perfect faith in God (AHRONI, 1982, p. 24). 
A pressão hermenêutica se dá, portanto, sobre três elementos que, aparentemente, não encontram mútua relação de identidade: a) a relação entre o deus-pastor e o rei, b) a mesa do, como se tem sugerido, "anfitrião" do salmista e c) os inimigos do salmista. Ora, talvez a tática de Ahroni possa ser aproveitada, conquanto se possa caminhar de modo distinto ao que ele pretendeu, aplicando a noção de metáfora ao bastão e ao cajado que, nesse caso, remeteriam a atributos do deus-pastor - Justiça e Misericórdia (AHRONI, 1982, p. 26-33). Sem me comprometer com o uso que Ahroni faz de sua própria tática, sirvo-me dela: "a (...) versatilidade metafórica que é característica deste Salmo enriquece a expressão dos sentimentos do poeta" ("the (...) metaphoric versatility which is characteristic of this Psalm enriches the expression of the poet's feelings"; AHRONI, 1982, p. 31). Nesse sentido, é no campo da metáfora que me parece estar a chave para superar a aparente falta de sentido entre os elementos "rei-pastor", "anfitrião" e "inimigos". Com o que se antecipa uma questão: não se trata exatamente da figura de um "anfitrião". Trata-se, a rigor, da mesa. É o fato de o salmista declarar que Yahweh preparará uma mesa diante dele, na presença de seus inimigos, que leva à interpretação de tratar-se, então, de um "anfitrião". Há, todavia, outra possibilidade.

\section{A "mesa na presença dos inimigos" na Bíblia Hebraica}

Se, como pensa Croft, o Salmo 23 "is very probably royal" (CROFT, 1987 , p. 77), se o salmista, portanto, encarna a identidade de um rei, se esse rei-salmista se depara com inimigos, e se, após derrotá-los (CROFT, 1987 , p. 130), Yahweh lhe prepara uma mesa diante desses mesmos inimigos derrotados, seria possível encontrar na Bíblia hebraica ao menos uma passagem em que rei, inimigos, vitória do rei e derrota dos inimigos estivessem associados à ideia de "mesa do rei"? Se sim, a impressão de fragilidade semântico-referencial entre os elementos do salmo assim tomados e interpretados se dissolveria. Pois a resposta é "sim!".

Muito genericamente, a "mesa do rei" aparece em várias passagens, como aquela em que, antes de sua morte, Davi instrui a Salomão, seu filho, a vingar-se de inimigos remanescentes do rei, mas a agir com benevolência com algumas personagens. No último caso, Davi pede a seu filho que os trate com misericórdia, de modo que "estarão entre os comedores da tua mesa"

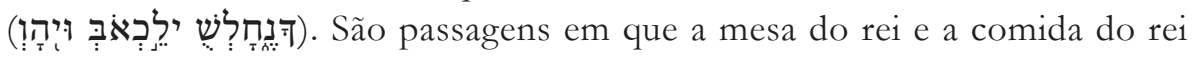
são sinais de benevolência dirigida àqueles que reconhecem o privilégio (2 Sm 9,7.10.11.13; 1 Rs 5,7; Ne 5,17), eventualmente assumido como imerecido (2 Sm 19,29). 
Essas passagens genéricas, todavia, não possuem a força retórica (GINZBURG, 2002) do episódio de Juízes 1,4b-7. Defendeu-se a tese de tratar-se do talvez mais antigo texto da Bíblia Hebraica: provavelmente, um antigo documento jebuseu, mantido nos arquivos de Jerusalém, e apropriado na montagem do livro de Juízes (RIBEIRO, 2012, p. 459-460 e 462). No texto, uma coalizão de cidades pré-israelitas, lideradas pela antiga "Jerusalém" jebusita, ataca a cidade de Bezeq, cujo rei, que até então as mantinha sob seu domínio, retendo seus reis, mutilados, em prisão no palácio real, foge e é perseguido. Capturado, tem os polegares das mãos e dos pés cortados, é levado para a antiga "Jerusalém" jebusita e ali é executado. Antes, porém, registra-se seu discurso de despedida: "Setenta reis, os polegares das mãos e dos pés cortados, tornaram-se recolhedores debaixo da minha mesa. Assim como eu fiz, assim retribuiu-me Deus" (RIBEIRO, 2012, p. 454). O que o rei de Bezeq parece estar dizendo é que ele havia se tornado senhor dos reis e das cidades da coalizão que, agora, o capturavam e executariam. Sob seu domínio, os reis das cidades da coalizão comiam do que caía de sua

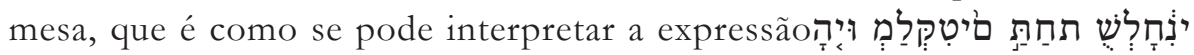

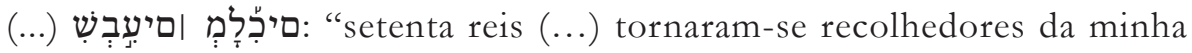
mesa". A cena que se deve imaginar é o salão real, a mesa real, sua fartura e poder ostentados, e os reis derrotados e capturados tendo, para comer, que humilhar-se diante da mão do poderoso monarca. Agora, sob o ódio e a vingança das cidades humilhadas, aqueles reis se vingam, sucesso que o texto faz o rei agora derrotado atribuir a acertos de contas da divindade.

Ora, talvez seja exatamente essa a imagem evocada no Salmo 23: uma mesa real, da qual comem, se o rei deseja, os inimigos humilhados do rei. A cena constitui propaganda do poder real: os "grandes da terra" comem, se o rei permite que comam, porque o rei é soberano. Nesse caso, o conjunto das referências do Salmo 23 poderia ser interpretado como descrevendo a circunstância em que um rei, o salmista, encontra-se em situação de perigo e ameaça por parte de não explicitamente identificados inimigos, mas, de qualquer modo, inimigos do rei, diante do que invoca a salvaguarda e a proteção divinas, a partir do que considera a vitória certa, e antevê o desfecho da situação: Yahweh preparará a mesa da vitória do rei, diante da qual os inimigos, derrotados, capitulam e reconhecem seu revés, com cujo final se estabelece a procedência da declaração de abertura do salmo: "Yahweh é meu pastor, não faltarei”. Não, não faltará. Mais do que isso: presidirá à mesa dos derrotados! 


\section{Considerações finais}

A despeito de considerar não ser metodologicamente adequado assumir a personagem do título redacional atribuído secundariamente à composição, o presente artigo partiu da intuição ${ }^{13}$ de que, de qualquer forma, o autor implícito do Salmo 23 seja um rei. Depois de investigar a hipótese de o primeiro versículo sustentar interpretação no sentido de considerar-se esse rei sob risco de vida, traduzindo-se, como permite a fenomenologia da raiz na Bíblia Hebraica, "Yahweh é meu pastor, não faltarei", isto é, "não serei 'derrotado e morto' pelos inimigos que me ameaçam”, passou-se a investigar a possibilidade de o tecido semântico do salmo possibilitar a articulação harmoniosa entre os elementos a) deus-pastor, b) rei, c) seus não identificados inimigos e d) a mesa que o deus-pastor lhe prepara na presença deles. A literatura testemunha caminhos de interpretação bastante diversos, e nenhum deles parece resolver satisfatoriamente a questão, chegando os mais ousados a promoverem alteração no próprio texto hebraico.

O resultado a que aqui se chega dá conta de que em pelo menos uma passagem da Bíblia Hebraica a articulação entre os elementos rei, divindade, inimigos e mesa se apresenta em surpreendente paralelo com a mesma conjunção do Salmo 23. A analogia entre o Salmo 23 e Juízes 1,4b-7 chega a ser impressionante. À luz da análise da passagem, e por meio do diálogo crítico com representantes da literatura especializada, foi possível postular o seguinte enredo geral para a composição do salmo: o rei se encontra ameaçado de morte, mas confia em Yahweh, de sorte que, a despeito da ameaça de morte ser a razão intrínseca da composição, é com a declaração de fé que se abre o poema: "Yahweh é meu pastor, não faltarei". O rei confia que sobreviverá. Seu temor deriva do fato de que inimigos (não identificados) ameaçam sua integridade física. Mas o salmista reconhece no bastão e no cajado de Yahweh as razões de sua proteção e segurança, de sorte que, ainda que ele caminhe por um vale de sombras, Yahweh o manterá vivo, de modo que ele não teme a desgraça. Mais ainda, malograda, a ameaça se reverterá sobre os inimigos do rei, que, derrotados, testemunharão a preparação da

13 "Intuição", porque: a) não se considera metodologicamente adequado assumir a autoria davídica da composição a partir do título secundário atribuído ao salmo, e b) porque, ainda que autores (como CROFT, 1987, p. 77) considerem seriamente a autoria monárquica do poema, a questão não está resolvida na pesquisa. O artigo pretende emprestar mais substância retórica à "intuição", de sorte que, ao final, seja ainda menos adequado empregar o termo para a questão. 
"mesa da vitória" - a mesa do rei - diante de seus olhos, o que, em termos traditivos, significa sua derrota e humilhação, bem como, em última análise, a demonstração de misericórdia por parte do rei que, em lugar de fazê-los "faltar", os manterá vivos, ainda que para contemplarem, dia e noite, pelos longos dias de sua vida, a vitória do rei que não "faltará".

Deriva(ria) da condição monárquica do compositor ou do autor implícito do salmo o tratamento privilegiado do deus como seu pastor. $\mathrm{Na}$ condição de monarca, o rei é o pastor do deus (como Ciro). O deus é o dono do rebanho, o proprietário das terras, mas é o rei, servo de Yahweh, o encarregado de cuidar do rebanho do deus. O rei é, nessa condição, pastor do deus, para pastorear o povo do deus. No salmo, a condição de quem tem o dever de proteger as ovelhas do deus é apropriada pelo próprio rei para, colocando-se na condição de "ovelha", e colocando o deus na condição de pastor dessa ovelha, poder o rei cobrir-se da confiança de que o bastão e o cajado do deus-pastor serão brandidos contra os seus inimigos, da mesma forma como o bastão e o cajado do rei são brandidos por ele contra os inimigos do povo do deus. Como o rei faz pelas ovelhas do deus, o deuspastor fará pela ovelha-rei - e nisso repousa a confiança do salmista.

Conclui-se, portanto, o artigo, com uma paráfrase do Salmo 23:

Gravemente, inimigos me ameaçam. Inimigos atentam contra a minha vida.

Mas um deus está comigo, e eu não sucumbirei "Yahweh é meu pastor, não faltarei"! Yahweh me levará aos campos verdejantes,

Yahweh me fará repousar junto às águas, Yahweh restaurará a minha vida, Yahweh me reconduzirá às sendas de justiça, por amor de seu nome.

Mas, enquanto eu caminhar pelo vale das sombras, não temerei desgraça: porque o teu bastão e o teu cajado me deixam seguro.

Nisso eu confio: não faltarei, porque tu ungiste a minha cabeça com óleo, o meu cálice de transbordamento! Por isso, tu me prepararás uma mesa de vitória, na presença de meus inimigos humilhados! Estou assim seguro de que a bondade e a misericórdia me seguirão todos os dias da minha vida, e habitarei na casa de Yahweh por longos dias... 


\section{Referências}

ALONSO-SCHÖKEL, L. Dicionário bíblico hebraico-português. São Paulo: Paulus, 1997.

ALONSO-SCHÖKEL, L. e CARNITI, C. Salmos I (Salmos 1-72). Tradução, introdução e comentário. São Paulo: Paulus, 1996.

AVIOZ, M. Nathan's oracle (2 Samuel 7) and its interpreters. Bern: Peter Lang, 2005.

BERnSTEIN, M. A Jewish Reading of Psalms. Some Observations on the Method of the Aramaic Targum. Em: FLINT, P. W. e MILLER JR., P. D. The book of Psalms. Composition and reception. Leiden: Brill, 2005, p. 476-504.

BOUZON, E. O Código de Hammurabi. Introdução, tradução do texto cuneiforme e comentários, 10. ed. Petrópolis: Vozes, 2003.

BUZON, E. As cartas de Hammurabi. Introdução, tradução do texto cuneiforme e comentários. Petrópolis: Vozes, 1986.

CAMPBELL, A. F. 2 Samuel. Grand Rapids: W. B. Eerdmans Publishing House, 2005.

CLINES, D. J. A. The Dictionary of Classical Hebrew. Volume V. Sheffield: Sheffield Academic Press, 2001.

COGGINS, R. e HAN, J. H. Six Minor Prophets Through the Centuries. Nahum, Habakkuk, Zephaniah, Haggai, Zechariah, and Malachi. West Sussex: John Wiley \& Sons, 2011.

COLE, R. D. Numbers. Nashville, B \& H Publishing House, 2000.

CROFT, S. J. L. The Identity of the Individual in the Psalms. Sheffield: Sheffield Academic Press, 1987.

D’ALARIO, V. Il libro del Qohelet. Struttura letteraria e retórica. Bologna: Edizioni Dehoniane Bologna, 1992.

EATON, G. Problems of translation in Psalm 23,3f. Bible Translator, n. 16, 1965, p. 171-176.

FREEEDMAN, D. N. The Twenty-third Psalm. Em CAMERON, G. G. e ORLIN, L. L. Studies in Honor of George G. Cameron. Michigan: Ann Arbor / University of Michigan, 1976, p. 139-166.

GINZBURG, C. Relações de Força. História, retórica, prova. São Paulo: Companhia das Letras, 2002.

GINZBURG, C. "Sinais: raízes de um paradigma indiciário." In: GINZBURG, C. Mitos, emblemas, sinais. São Paulo: Companhia das Letras, 2007, p. 143-180.

HAMILTON, V. P. The Book of Genesis. Chapters 18-50. Grand Rapids: W. B. Eerdmans Publishing House, 1995. 
HILL, J. Friend or Foe? The Figure of Babylon in the Book of Jeremiah MT. Leiden: Brill, 1999. HOLLADAY, W. L. Léxico hebraico e aramaico do Antigo Testamento. São Paulo: Vida Nova, 2010. KAMIONKOWSKI, S. T. Gender Reversal and Cosmic Chaos. A Study on the Book of Ezekiel. Sheffield: Sheffield Academic Press, 2003.

KRAUS, H.-J. Los Salmos 1-59. Salamanca: Sígueme, 2009.

MASON, R. Micah, Nahum and Obadiah. London: T \& T Clark, 2004.

McKEATING, H. Ezekiel. Sheffield: Sheffield Academic Press, 1993.

MISCALL, P. D. Isaiah, 2nd ed. Sheffield: Sheffield Academic Press, 2006.

MORGENSTERN, J. 1946. Psalm 23. Journal of Biblical Literature, v. 65, 1946, p. 13-24.

RIBEIRO, O. L. Bünê ’ädäm. Os “filhos de homem” na Bíblia Hebraica. Reflexus, n. 5, v. 6, 2011.

RIBEIRO, O. L. "E o levaram para Jerusalém e o mataram lá.” Juízes 1,4b-7 como documento jebuseu dos arquivos de Jerusalém. Perspectiva Teológica, v. 44, n. 124, 2012, p. 451-466.

RIBEIRO, O. L. Salmo 53. Quando os pastores são leões. In: CARNEIRO, M. Bíblia e cultura. Tradição, tradução e exegese. Debatendo as diferentes leituras da Bíblia. São Paulo: Fonte / ABIB, 2014.

RIBEIRO, O. L. Salmo 89. Crise e quebra dinástica como anti-cosmogonia. Oracula, v. 5, n. 9, 2009.

RIBEIRO, O. L. Sintaxe e semântica de רס na Bíblia Hebraica: estudo para a tradução do Salmo 23. Pistis e Praxis, v. 9, n. 3, 2017a, p. 721-739.

RIBEIRO, O. L. "Yahweh é meu pastor. Não faltarei." Uma proposta de tradução e interpretação para o Salmo 23. Teoliterária, v. 7, n. 13, 2017b, p. 305-326.

SCHÖKEL, L.-A. Dicionário Bíblico Hebraico-Português. São Paulo: Paulus, 1997.

SYLVA, D. Psalms and the Transformation of Stress: Poetic-communal Interpretation and the family. Grand Rapids: W. B. Eerdmans, 1993.

UNTERMAN, J. From Repentance to Redemption. Jeremiah's Thought in Transicion. Sheffield: Sheffield Academic Pres, 1987.

WASSERMAN, A. e SZWERTSZARF, C. Salmos. Rio de Janeiro: Mcklausen, s/d.

WEISER, A. Os Salmos. São Paulo: Paulus, 1994.

Submetido em: 25-10-2017

Aceito em: 11-4-2019 